\title{
RESEARCH
}

\section{Frequency of adverse events in patients with poor anticoagulation: a meta-analysis}

\author{
Natalie Oake, Dean A. Fergusson, Alan J. Forster, Carl van Walraven
}

\section{ABSTRACT}

Background: Patients taking anticoagulants orally over the long term have international normalized ratios (INRs) outside the individual therapeutic range more than one-third of the time. Improved anticoagulation control will reduce hemorrhagic and thromboembolic event rates. To gauge the potential effect of improved anticoagulation control, we undertook to determine the proportion of anticoagulant-associated events that occur when INRs are outside the therapeutic range.

Methods: We conducted a meta-analysis of all studies that assigned hemorrhagic and thromboembolic events in patients taking anticoagulants to discrete INR ranges. We identified studies using the MEDLINE (1966-2006) and EMBASE (1980-2006) databases. We included studies reported in English if the majority of patients taking oral anticoagulants had an INR range with a lower limit between 1.8 and 2 and an upper limit between 3 and 3.5 , and their INR at the time of the hemorrhagic or thromboembolic event was recorded.

Results: The final analysis included results from 45 studies ( 23 that reported both hemorrhages and thromboemboli; 14 that reported hemorrhages only; and 8, thromboemboli only) involving a median of 208 patients (limits of interquartile range [25th $-75^{\text {th }}$ percentile] $131^{1-523}$ subjects; total $n=$ 71065 ). Of these studies, $64 \%$ were conducted at community practices; the remainder, at anticoagulation clinics. About $69 \%$ of the studies were classed as having moderate or high quality. Overall, $44 \%$ (95\% confidence interval $[\mathrm{CI}]$ $39 \%-49 \%$ ) of hemorrhages occurred when INRs were above the therapeutic range, and $48 \%(95 \% \mathrm{Cl} 41 \%-55 \%)$ of thromboemboli took place when below it. The mean proportion of events that occurred while the patient's INR was outside the therapeutic range was greater for studies with a short mean follow-up ( $<1 \mathrm{yr}$ ). Between-study heterogeneity was significant $(p<0.001)$

Interpretation: Improved anticoagulation control could decrease the likelihood of almost half of all anticoagulantassociated adverse events.

CMAJ 2007;176(II):1589-94

$\mathrm{P}$ atients taking anticoagulants orally over the long term have international normalized ratios (INRs) that fall outside the individual therapeutic range more than one-third of the time. ${ }^{1}$ Improved anticoagulation control re- duces hemorrhagic and thromboembolic event rates. ${ }^{2,3}$ Many studies have shown that such event rates are higher when patients' INRs are outside the therapeutic range. ${ }^{4-11}$ A study that systematically measures the proportion of hemorrhages and thromboemboli that occur when INRs are above and below the therapeutic range, respectively, will help both physicians and policy-makers gauge the potential effect of improved anticoagulation control. In our investigation, we measured and analyzed these proportions.

\section{Methods}

We identified pertinent citations in English in the MEDLINE (1966-2006) and EMBASE (I980-2006) databases using the search strategy outlined in Appendix I. This strategy combined medical subject headings and keywords related to anticoagulation (e.g., anticoagulants, warfarin) and to hemorrhages and thromboemboli (e.g., cerebrovascular accident, bleed). We retrieved the full text of articles for further review if the title or abstract suggested that patients taking anticoagulants were studied and data on hemorrhages or thromboemboli were reported. Studies were included in our review if the majority of patients taking anticoagulants orally had an INR range with a lower limit between $\mathrm{I} .8$ and 2 and an upper limit between 3 and 3.5, and the INR at the time of the hemorrhagic or thromboembolic event was recorded; these limits represent the most common therapeutic ranges for patients taking oral anticoagulants. All citations and studies were reviewed for inclusion by a single author (N.O.). We considered all major hemorrhages (i.e., those that required hospital admission, a transfusion or surgery, or that reduced hemoglobin levels by $\geq 20 \mathrm{~g} / \mathrm{L}$ ) and thromboemboli (stroke, myocardial infarction, venous thromboembolism or systemic emboli, confirmed by objective tests). We excluded patient groups taking anticoagulants by mouth with concomitant antiplatelet therapy, because their risk of hemorrhagic and thromboembolic events is considerably higher than the risks of patients taking anticoagulants alone. ${ }^{12,13}$

From each study, we abstracted the total number of major hemorrhages and thromboemboli that could be assigned to particular INR ranges. Some studies assigned events to INRs based on measurements taken at the time of the event or at hospital admission, whereas others used measurements made beforehand to approximate the INR at the time of the event. We grouped the events into 3 INR ranges: below, 
within and above the therapeutic range. For each study, we then calculated the proportion of major hemorrhages that occurred when INRs exceeded the therapeutic range and the proportion of thromboemboli when INRs fell below it.

We used a random effects model to pool individual study estimates into an overall mean proportion of hemorrhages that occurred above therapeutic range and overall mean proportion of thromboemboli that occurred below therapeutic range. In both models, individual studies were weighted by the inverse of their variance. ${ }^{14}$

We used linear regression models to explain betweenstudy heterogeneity by determining if the proportion of events that occurred when INRs were outside the therapeutic range was associated with study-level factors, including mean patient age, mean follow-up time, study setting, target INR range, type of anticoagulant used (e.g., warfarin, acenocoumarol, phenprocoumon) and study quality. We measured study quality using key study design components suggested by the MOOSE Group ${ }^{15}$ and presented in the NewcastleOttawa Scale. ${ }^{16}$ These components included the external validity of the study cohort, appropriateness of outcome assessment, and adequacy of follow-up. We classified studies as high quality if they included patients who represented the average user of anticoagulants taken by mouth, used blind evaluation or record linkage to assess events, and either reported a complete follow-up or provided a description of patients lost to follow-up; as moderate quality, if 2 of these 3 criteria were satisfied; and all others as low quality. We generated all linear regression models in SAS software using its GLM (general linear models) Procedure, with individual studies weighted by the inverse of variance. We stratified the meta-analyses by all factors that were significantly associated $(p<0.05)$ with the proportion of events occurring outside therapeutic range.

Finally, we also determined if the proportion of hemorrhagic or thromboembolic events occurring above or below the therapeutic INR range was associated with the proportion of overall time spent outside the range by abstracting the proportion of time spent above and below the therapeutic range from each study. We investigated this association using linear regression models, as described in the preceding paragraph.

\section{Results}

The literature search yielded 3220 citations, of which 362 articles were retrieved and reviewed. We excluded studies that did not monitor patients within the appropriate INR range $(n=29)$ and studies that did not assign events to particular INR ranges $(n=288)$.

The final analysis included results from 45 studies: 23 that reported both hemorrhages and thromboemboli; ${ }^{17-39}$ I4 that reported hemorrhages only; ${ }^{4,7,40-51}$ and 8 , thromboemboli only. ${ }^{8,9,52-57}$ The studies included a median of 208 patients (limits of interquartile range [ $25^{\text {th }}-75^{\text {th }}$ percentile] $\mathrm{I} 3 \mathrm{I}-523$ subjects; total $n=71065)$. About two-thirds of the studies $(64 \%)$ were conducted at community practices; the remainder, at anticoagulation clinics. Study quality was classed as being moderate or high in $69 \%$. Most studies $(70 \%)$ involved patients with various conditions requiring anticoagulant drugs. Only $9 \%$ of the studies did not use blind assessment or record linkage to assess hemorrhagic or thromboembolic events. Half of the studies reported a complete follow-up. It is noteworthy that one-third of studies did not assign all of the events recorded to particular INR ranges. Also, I3 studies (29\%) utilized a previous INR measurement, taken 2-30 days before the actual hemorrhagic or thromboembolic event, to approximate the INR at the time of the event.

Overall, $44 \%$ ( $95 \%$ confidence interval [CI] $39 \%-49 \%$ ) of hemorrhages occurred at INRs above the therapeutic range, whereas $48 \%$ ( $95 \% \mathrm{CI} 4 \mathrm{I} \%-55 \%$ ) of thromboemboli occurred at INRs below therapeutic range (Fig. I and Fig. 2). However, the regression models found that mean follow-up time was the only study-level factor that was significantly associated with the proportion of events that occurred outside the therapeutic INR range. Therefore, the meta-analyses were stratified by mean follow-up time: less than or exceeding I year. Studies with a mean follow-up time of less than I year had a greater proportion of events at extreme INRs (Fig. I and Fig. 2), although these proportions did not differ significantly from studies with a longer follow-up time. ${ }^{58}$ Both meta-analyses noted significant between-study heterogeneity $(p<0.00 I)$.

Twenty-one of the included studies (47\%) reported the proportion of total observation time along with either hemorrhages occurring above the therapeutic INR range (I8 studies, ${ }^{4,17-29,40-43} 40 \%$ ) or thromboemboli occurring below it (I6 studies, ${ }^{8,17-29,52,53} 36 \%$ ). The proportion of time spent with INRs below the therapeutic range in each study was significantly associated with the proportion of thromboemboli occurring below range $(p<0.05)$. Studies in which patients spent more time with INRs below the therapeutic range had a significantly higher proportion of thromboembolic events below range. Proportion of time spent above range was not, however, significantly associated with the proportion of hemorrhages occurring at INR levels above the therapeutic range.

\section{Interpretation}

We found that about half of all hemorrhages occur above and half of all thromboemboli occur below the therapeutic range for INR. Mean study length of follow-up was associated with the proportion of events that occur outside the therapeutic range. We also found that the proportion of thromboemboli occurring at INRs below the therapeutic range was greater with increased time spent at INRs below the range.

Although half of all anticoagulation events occurred at INRs outside the therapeutic range, we believe it equally notable that half of all events did not. Other factors, such as patient age and comorbidities, may be contributing to these events. ${ }^{59-62}$ It is also noteworthy that, of the half of all events associated with anticoagulants taken orally that occurred outside the therapeutic range, not all would have been avoided with perfect anticoagulation quality. Knowledge of the population-attributable risk is required to estimate the effect of improved anticoagulation on event rates. ${ }^{63}$

Our review found that shorter mean follow-up time was associated with a greater proportion of events outside range. 
This could be due to incident patients having worse anticoagulation control than prevalent users. ${ }^{64}$ To account for this difference in patients across studies, we stratified the metaanalyses by a mean follow-up cut-off of I year. Despite this, significant heterogeneity persisted between the studies. This is not surprising, since heterogeneity is high when results from observational studies are pooled. ${ }^{65}$ Moreover, the statistical power to explain heterogeneity by means of study-level variables was limited. More information about patient-level factors associated with the proportion of time spent with the patient within the therapeutic INR range ${ }^{66}$ would likely better explain heterogeneity between studies.

We found that the proportion of thromboemboli occurring below therapeutic range was significantly greater when time spent below range increased. This result reinforces the findings of Veeger and colleagues, ${ }^{2}$ who reported signifi-

Proportion and confidence interval

\begin{tabular}{|c|c|c|c|}
\hline Study & e range/total* & weight, \% & $(95 \% \mathrm{CI})$ \\
\hline \multicolumn{4}{|c|}{ Mean follow-up $<1 \mathrm{yr}$} \\
\hline Kearon ${ }^{43}$ & $3 / 3$ & 0.00 & $1.00(0.00-1.00)$ \\
\hline Chiquette $^{28}$ & $5 / 6$ & 4.37 & $0.83(0.36-0.97)$ \\
\hline Gras-Champel ${ }^{39}$ & $4 / 7$ & 6.90 & $0.57(0.22-0.85)$ \\
\hline Hutten ${ }^{24}$ & $3 / 11$ & 7.82 & $0.27(0.08-0.58)$ \\
\hline Punthakee ${ }^{44}$ & $7 / 11$ & 8.43 & $0.64(0.34-0.85)$ \\
\hline Hirri $^{45}$ & $17 / 21$ & 9.37 & $0.81(0.58-0.92)$ \\
\hline Beyth ${ }^{41}$ & $11 / 20$ & 10.91 & $0.55(0.33-0.74)$ \\
\hline Palareti ${ }^{4}$ & $10 / 25$ & 11.53 & $0.40(0.23-0.59)$ \\
\hline Moherman $^{35}$ & $13 / 46$ & 12.74 & $0.28(0.17-0.42)$ \\
\hline Cantalapiedra $a^{51}$ & $25 / 45$ & 13.16 & $0.56(0.41-0.69)$ \\
\hline Torn 32 & $45 / 155$ & 14.76 & $0.29(0.22-0.36)$ \\
\hline Summary estima & & & $0.48(0.36-0.61)$ \\
\hline \multicolumn{4}{|c|}{ Mean follow-up > $1 \mathrm{yr}$} \\
\hline Goldberg $^{19}$ & $0 / 3$ & 0.00 & $0.00(0.00-1.00)$ \\
\hline Agnelli ${ }^{47}$ & $0 / 4$ & 0.00 & $0.00(0.00-1.00)$ \\
\hline Ames $^{17}$ & $2 / 3$ & 0.80 & $0.67(0.15-0.95)$ \\
\hline Bona $^{34}$ & $2 / 3$ & 0.80 & $0.67(0.15-0.95)$ \\
\hline Evans $^{23}$ & $2 / 3$ & 0.80 & $0.67(0.15-0.95)$ \\
\hline Gulløv 49 & $1 / 4 / 1 / 4$ & 0.90 & $0.25(0.03-0.76)$ \\
\hline Chan $^{40}$ & $4 / 5$ & 0.95 & $0.80(0.30-0.97)$ \\
\hline Connolly ${ }^{26}$ & $1 / 5$ & 0.95 & $0.20(0.02-0.69)$ \\
\hline Yamaguchi ${ }^{33}$ & $1 / 6$ & 1.00 & $0.17(0.02-0.63)$ \\
\hline Pengo 25 & $4 / 6$ & 1.51 & $0.67(0.27-0.91)$ \\
\hline Kearon ${ }^{21}$ & $4 / 8$ & 2.16 & $0.50(0.20-0.80)$ \\
\hline Andersen ${ }^{29}$ & $11 / 14$ & 2.45 & $0.79(0.51-0.93)$ \\
\hline SPAF $^{50}$ & $7 / 11$ & 2.63 & $0.64(0.34-0.85)$ \\
\hline Copland ${ }^{46}$ & $6 / 11$ & 2.79 & $0.55(0.27-0.80)$ \\
\hline Njaastad ${ }^{36}$ & $6 / 18$ & 3.74 & $0.33(0.15-0.56)$ \\
\hline Poli22 & $7 / 19$ & 4.04 & $0.37(0.18-0.59)$ \\
\hline Chimowitz $^{18}$ & $14 / 24$ & 4.89 & $0.58(0.38-0.75)$ \\
\hline Casais $^{42}$ & $12 / 25$ & 5.10 & $0.48(0.29-0.66)$ \\
\hline Yousef ${ }^{30}$ & $12 / 28$ & 5.41 & $0.43(0.26-0.61)$ \\
\hline Albers ${ }^{31}$ & $18 / 41$ & 6.75 & $0.44(0.29-0.59)$ \\
\hline Berwaerts ${ }^{48}$ & $20 / 42$ & 6.88 & $0.48(0.33-0.62)$ \\
\hline Holm 37 & $22 / 43$ & 6.96 & $0.51(0.36-0.65)$ \\
\hline Newman 38 & $19 / 46$ & 7.09 & $0.41(0.27-0.55)$ \\
\hline Albers ${ }^{20}$ & $20 / 84$ & 8.21 & $0.24(0.16-0.34)$ \\
\hline van Walraven ${ }^{27}$ & $75 / 200$ & 11.44 & $0.37(0.31-0.44)$ \\
\hline Oden 7 & $82 / 243$ & 11.74 & $0.33(0.28-0.39)$ \\
\hline \multicolumn{3}{|c|}{ Summary estimate } & $0.43(0.37-0.48)$ \\
\hline \multicolumn{3}{|c|}{ Overall estimate } & $0.44(0.39-0.49)$ \\
\hline
\end{tabular}

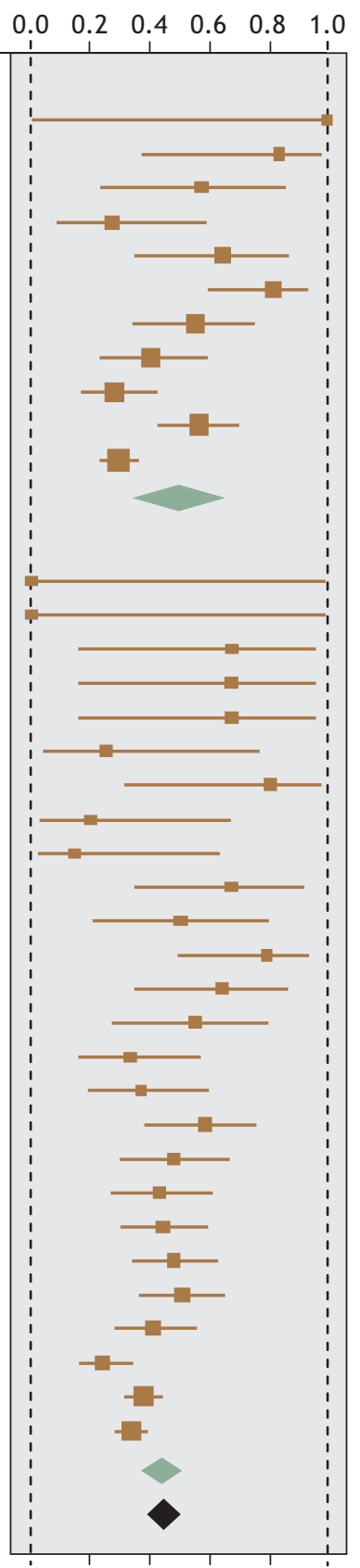

Note: $\mathrm{Cl}=$ confidence interval.

*Number of hemorrhages that occurred while the patient's international normalized ratio (INR) was above the therapeutic range, out of the total number of these events.

Fig. 1: Proportion of hemorrhagic events in each study that occurred when patients' INRs were above the therapeutic range, with summary estimates from the random-effects meta-analysis. 
cantly higher rates of thromboembolic events with increased time spent outside the therapeutic INR range. Unlike Veeger's group, however, we did not find that the proportion of hemorrhages occurring above range increased with the proportion of time spent above range.

Our study is important because it systematically measured the proportion of hemorrhages and thromboemboli that occur when INRs are above and below the therapeutic range, respectively. Our results should encourage physicians and policy makers to evaluate and implement interventions, such as anticoagulation clinics ${ }^{1,67}$ and patient self-management, ${ }^{68,69}$ that improve anticoagulation control.

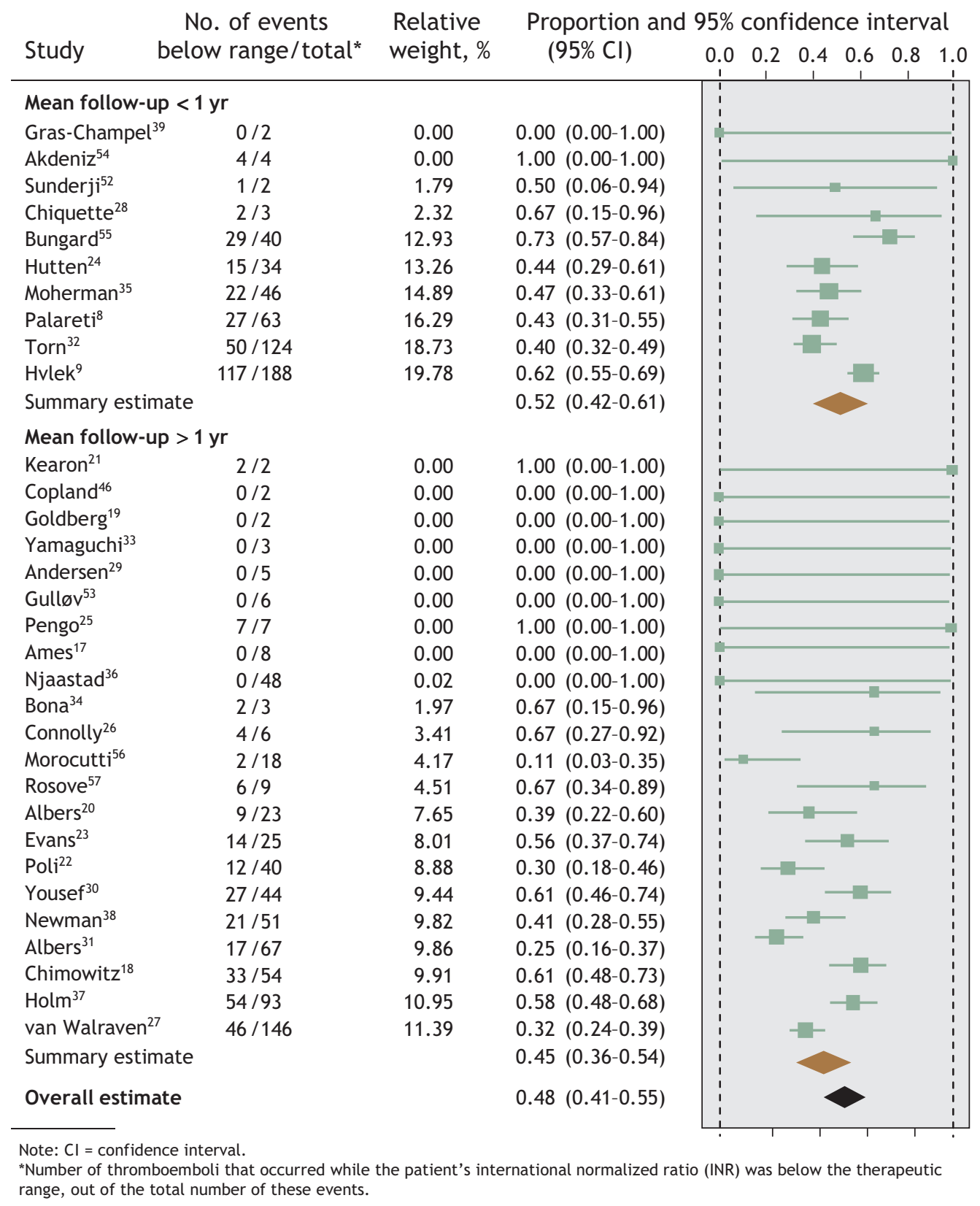

Fig. 2: Proportion of thromboembolic events in each study that occurred when patients' INRs were below the therapeutic range, with summary estimates from the random-effects meta-analysis.
Our study is not without limitations. Studies may have been missed despite our comprehensive search. The number of events assigned to INR levels in studies may be biased, since one-third of the studies did not assign all of the events to INR ranges and $28 \%$ of the studies used previously measured INRs to approximate the level of anticoagulation at the time of the events. Studies reported slight variations of target therapeutic range. And finally, we were unable to examine the difference in the proportion of events that occurred outside the therapeutic INR range by anticoagulation indication, because more than half of the studies included patients with different indications for taking anticoagulants. Further research 
(ideally with individual patient data) is required to determine if the proportion of anticoagulant-associated events that occur outside the therapeutic range of INRs varies with indication for anticoagulant use.

In conclusion, we found that improved anticoagulation control could decrease the likelihood of almost half of all adverse events associated with anticoagulants taken orally.

\section{This article has been peer reviewed.}

From the Department of Medicine, University of Ottawa (all authors); the Clinical Epidemiology Program (Oake, Fergusson, Forster), Ottawa Health Research Institute, Ottawa; and the Institute for Clinical Evaluative Science (van Walraven), Toronto, Ont.

Competing interests: None declared.

Contributors: The systematic review and meta-analysis was developed and designed by Natalie Oake and Carl van Walraven; Ms. Oake conducted the literature search and abstracted the data. Dean Fergusson helped with the methodology, and Alan Forster with clinical content. All authors participated in the data analysis, interpretation of results, and critical revision of the manuscript. All authors approved the final version for publication.

\section{REFERENCES}

I. van Walraven $\mathrm{C}$, Jennings $\mathrm{A}$, Oake $\mathrm{N}$, et al. Effect of study setting on anticoagulation control: a systematic review and metaregression. Chest 2006;129:1155-66.

2. Veeger NJGM, Piersma-Wichers M, Hillege HL, et al. Early detection of patients with a poor response to vitamin $\mathrm{K}$ antagonists: the clinical impact of individual time within target range in patients with heart disease. J Thromb Haemost 2006;4: I625-7.

3. Veeger NJGM, Piersma-Wichers M, Tijssen JG, et al. Individual time within target range in patients treated with vitamin $\mathrm{K}$ antagonists: main determinant of quality of anticoagulation and predictor of clinical outcome. A retrospective study of 2300 consecutive patients with venous thromboembolism. BrJ Haematol 2005; I28:5I3-9.

4. Palareti G, Leali N, Coccheri S, et al. Bleeding complications of oral anticoagulant treatment: an inception-cohort, prospective collaborative study (ISCOAT). Italian Study on Complications of Oral Anticoagulant Therapy. Lancet I996;348:423-8.

5. Torn M, Algra A, Rosendaal FR. Oral anticoagulation for cerebral ischemia of arterial origin: high initial bleeding risk. Neurology 200I;57:I993-9.

6. Tangelder MJ, Algra A, Lawson JA, et al. Optimal oral anticoagulant intensity to prevent secondary ischemic and hemorrhagic events in patients after infrainguinal bypass graft surgery. J Vasc Surg 200I;33:522-7.

7. Oden A, Fahlen M. Oral anticoagulation and risk of death: a medical record linkage study. BMJ 2002;325:1073-5.

8. Palareti G, Manotti C, DAngelo A, et al; Italian Study on Complications of Oral Anticoagulant Therapy (ISCOAT) Study Group. Thrombotic events during oral anticoagulant treatment: results of the inception-cohort, prospective, collaborative ISCOAT study. Thromb Haemost 1997;78:1438-43.

9. Hylek EM, Go AS, Chang Y, et al. Effect of intensity of oral anticoagulation on stroke severity and mortality in atrial fibrillation. N Engl J Med 2003;349:1019-26.

Io. Oden A, Fahlen M, Hart RG. Optimal INR for prevention of stroke and death in atrial fibrillation: a critical appraisal. Thromb Res 2006;117:493-9.

II. Cannegieter SC, Rosendaal FR, Wintzen AR, et al. Optimal oral anticoagulant therapy in patients with mechanical heart valves. N Engl J Med I995;333:II-7.

I2. Larson RJ, Fisher ES. Should aspirin be continued in patients started on warfarin? J Gen Inter Med 2004;19:879-86.

13. Little SH, Massel DR. Antiplatelet and anticoagulation for patients with prosthetic heart valves. Cochrane Database Syst Rev 2003;(4):CDoo3464

I4. Khan KS, Kunz R, Kleijnen J, et al. Systematic reviews to support evidence-based medicine: how to review and apply findings to healthcare research. London (UK): Royal Society of Medicine Press; 2003.

I5. Stroup DF, Berlin JA, Morton SC, et al; Meta-analysis of Observational Studies in Epidemiology (MOOSE) Group. Meta-analysis of observational studies in epidemiology: a proposal for reporting. JAMA 2000;283:2008-I2.

I6. Haynes RB, Sackett DL, Guyatt GH, et al. Clinical epidemiology: how to do clinical practice research. 3 rd edition. Philadelphia: Lippincott Williams \& Wilkins; 2005.

17. Ames PR, Ciampa A, Margaglione $M$, et al. Bleeding and re-thrombosis in primary antiphospholipid syndrome on oral anticoagulation: an 8-year longitudinal comparison with mitral valve replacement and inherited thrombophilia. Thromb Haemost 2005;93:694-9.

I8. Chimowitz MI, Lynn MJ, Howlett-Smith $\mathrm{H}$, et al. Comparison of warfarin and aspirin for symptomatic intracranial arterial stenosis. N Engl J Med 2005;352:1305-I6.

I9. Goldberg Y, Meytes D, Shabtai E, et al. Monitoring oral anticoagulant therapy by telephone communication. Blood Coagul Fibrinolysis 2005;16:227-30.
20. Albers GW, Diener HC, Frison L, et al. Ximelagatran vs warfarin for stroke prevention in patients with nonvalvular atrial fibrillation: a randomized trial. JAMA 2005 293:690-8.

2I. Kearon C, Ginsberg JS, Kovacs MJ, et al. Comparison of low-intensity warfarin therapy with conventional-intensity warfarin therapy for long-term prevention of recurrent venous thromboembolism. N Engl J Med 2003;349:63I-9.

22. Poli D, Antonucci E, Lombardi A, et al. Low rate of bleeding and thrombotic complications of oral anticoagulant therapy independent of age in the real-practice of an anticoagulation clinic. Blood Coagul Fibrinolysis 2003;I4:269-75.

23. Evans A, Perez I, Yu G, et al. Secondary stroke prevention in atrial fibrillation: lessons from clinical practice. Stroke 2000;31:2106-II.

24. Hutten BA, Prins MH, Gent M, et al. Incidence of recurrent thromboembolic and bleeding complications among patients with venous thromboembolism in relation to both malignancy and achieved international normalized ratio: a retrospective analysis. J Clin Oncol 2000;18:3078-83.

25. Pengo V, Zasso A, Barbero F, et al. Effectiveness of fixed minidose warfarin in the prevention of thromboembolism and vascular death in nonrheumatic atrial fibrillation. Am J Cardiol I998;82:433-7.

26. Connolly SJ, Laupacis A, Gent M, et al. Canadian Atrial Fibrillation Anticoagulation (CAFA) Study. J Am Coll Cardiol I991;18:349-55.

27. van Walraven C, Oake N, Wells PC, et al. Burden of potentially avoidable anticoagulant-associated hemorrhagic and thromobembolic events in the elderly. Chest, 2007; Feb 22 [Epub ahead of print]. DOI:I0.1378/chest.06-2628.

28. Chiquette E, Amato MG, Bussey HI. Comparison of an anticoagulation clinic with usual medical care: anticoagulation control, patient outcomes, and health care costs. Arch Intern Med I998;158:164I-7.

29. Andersen PV, Aagaard J. Low-dose warfarin in patients with Carbomedics heart valve prostheses. Asian Cardiovasc Thorac Ann 2000;8:II-4.

30. Yousef ZR, Tandy SC, Tudor V, et al. Warfarin for non-rheumatic atrial fibrillation: five year experience in a district general hospital. Heart 2004;90:1259-62.

31. Olsson SB; Executive Steering Committee on behalf of the SPORTIF III Investigators. Stroke prevention with the oral direct thrombin inhibitor ximelagatran compared with warfarin in patients with non-valvular atrial fibrillation (SPORTIF III): randomised controlled trial. Lancet 2003;362:169I-8.

32. Torn M, Rosendaal FR. Oral anticoagulation in surgical procedures: risks and recommendations. BrJ Haematol 2003;123:676-82.

33. Yamaguchi T. Optimal intensity of warfarin therapy for secondary prevention of stroke in patients with nonvalvular atrial fibrillation: a multicenter, prospective, randomized trial. Stroke 2000;3I:8I7-2I.

34. Bona $\mathrm{RD}$, Sivjee $\mathrm{KY}$, Hickey $\mathrm{AD}$, et al. The efficacy and safety of oral anticoagulation in patients with cancer. Thromb Haemost 1995;74:1055-8.

35. Moherman LJ, Kolar MM. Complication rates for a telephone-based anticoagulation service. Am J Health Syst Pharm I999;56:1540-2.

36. Njaastad AM, Abildgaard U, Lassen JF. Gains and losses of warfarin therapy as performed in an anticoagulation clinic. J Intern Med 2006;259:296-304.

37. Holm T, Lassen JF, Husted SE, et al. A randomized controlled trial of shared care versus routine care for patients receiving oral anticoagulant therapy. J Intern Med 2002;252:322-3I.

38. Newman DH, Zhitomirsky I. The prevalence of nontherapeutic and dangerous international normalized ratios among patients receiving warfarin in the emergency department. Ann Emerg Med 2006;48:182-9.

39. Gras-Champel V, Voyer A, Guillaume N, et al. Quality evaluation of the management of oral anticoagulation therapy (OAT): the awareness of treating physicians and the education of patients needs to be improved. Am J Ther 2006;13:223-8.

40. Chan TY, Miu KY. Hemorrhagic complications of anticoagulant therapy in Chinese patients. JChin Med Assoc 2004;67:55-62.

4I. Beyth RJ, Quinn L, Landefeld CS. A multicomponent intervention to prevent major bleeding complications in older patients receiving warfarin: a randomized, controlled trial. Ann Intern Med 2000;133:687-95.

42. Casais P, Luceros AS, Meschengieser S, et al. Bleeding risk factors in chronic ora anticoagulation with acenocoumarol. Am J Hematol 2000;63:192-6.

43. Kearon C, Gent M, Hirsh J, et al. A comparison of three months of anticoagulation with extended anticoagulation for a first episode of idiopathic venous thromboembolism. NEngI J Med I999;340:90I-7.

44. Punthakee X, Doobay J, Anand SS. Oral-anticoagulant-related intracerebral hemorrhage. Thromb Res 2002;108:31-6.

45. Hirri HM, Green PJ. Audit of anticoagulant therapy and acute hospital admissions. Clin Lab Haematol 2002;24:43-5.

46. Copland M, Walker ID, Tait RC. Oral anticoagulation and hemorrhagic complications in an elderly population with atrial fibrillation. Arch Intern Med 2001;16r: 2125-8.

47. Agnelli G, Prandoni P, Santamaria MG, et al. Three months versus one year of ora anticoagulant therapy for idiopathic deep venous thrombosis. N Engl J Med 200I 345:I65-9.

48. Berwaerts J, Dijkhuizen RS, Robb OJ, et al. Prediction of functional outcome and in-hospital mortality after admission with oral anticoagulant-related intracerebral hemorrhage. Stroke 2000;31:2558-62.

49. Gull $\phi v$ AL, Koefoed BG, Petersen P. Bleeding during warfarin and aspirin therapy in patients with atrial fibrillation: the AFASAK 2 study. Atrial Fibrillation Aspirin and Anticoagulation. Arch Intern Med 1999;159:1322-8.

50. Stroke Prevention in Atrial Fibrillation Investigators. Adjusted-dose warfarin versus low-intensity, fixed-dose warfarin plus aspirin for high-risk patients with atria fibrillation: Stroke Prevention in Atrial Fibrillation III randomised clinical trial. Lancet $1996 ; 348: 633-8$. 
5I. Cantalapiedra A, Gutierrez O, Tortosa JI, et al. Oral anticoagulant treatment: risk factors involved in 500 intracranial hemorrhages. J Thromb Thrombolysis 2006; 22:113-20.

52. Sunderji R, Gin K, Shalansky K, et al. A randomized trial of patient self-managed versus physician-managed oral anticoagulation. Can J Cardiol 2004;20:1117-23.

53. Gull $\phi v$ AL, Koefoed BG, Petersen P, et al. Fixed minidose warfarin and aspirin alone and in combination vs adjusted-dose warfarin for stroke prevention in atria fibrillation: Second Copenhagen Atrial Fibrillation, Aspirin, and Anticoagulation Study. Arch Intern Med 1998; I58:I5I3-2I.

54. Akdeniz B, Turker S, Ozturk V, et al. Cardioversion under the guidance of transesophageal echochardiograhy in persistent atrial fibrillation: results with low molecular weight heparin. Int J Cardiol 2005;98:49-55

55. Bungard TJ, Ackman ML, Ho G, et al. Adequacy of anticoagulation in patients with atrial fibrillation coming to a hospital. Pharmacotherapy 2000;20:1060-5.

56. Morocutti C, Amabile G, Fattapposta F, et al. Indobufen versus warfarin in the secondary prevention of major vascular events in nonrheumatic atrial fibrillation. Stroke I997;28:1015-2I.

57. Rosove MH, Brewer PM. Antiphospholipid thrombosis: clinical course after the first thrombotic event in 70 patients. Ann Intern Med I992;117:303-8.

58. Payton ME, Greenstone $\mathrm{MH}$, Schenker N. Overlapping confidence intervals or standard error intervals: what do they mean in terms of statistical significance? J Insect Sci 2003;3:34.

59. Butchart EG, Payne N, Li HH, et al. Better anticoagulation control improves survival after valve replacement. J Thorac Cardiovasc Surg 2002;123:715-23

6o. Hylek EM, Singer DE. Risk factors for intracranial hemorrhage in outpatients taking warfarin. Ann Intern Med 1994;120:897-902.

6r. Landefeld CS, Goldman L. Major bleeding in outpatients treated with warfarin incidence and prediction by factors known at the start of outpatient therapy. Am J Med I989;87:I44-52.

62. Gorter JW. Major bleeding during anticoagulation after cerebral ischemia: patterns and risk factors. Neurology 1999;53:1319-27.

63. Hanley JA. A heuristic approach to the formulas for population attributable frac tion. J Epidemiol Community Health 200I; 55:508-I4.

64. ACTIVE Writing Group on behalf of the ACTIVE Investigators. Clopidogrel plus aspirin versus oral anticoagulation for atrial fibrillation in the Atrial Fibrillation Clopidogrel Trial with Irbesartan for Prevention of Vascular Events (ACTIVE W) randomised controlled trial. Lancet 2006;367:1903-I2.

65. Berlin JA. Invited commentary: benefits of heterogeneity in meta-analysis of data from epidemiologic studies. Am J Epidemiol I995;I42:383-7.

66. van Walraven $\mathrm{C}$, Austin $\mathrm{PC}$, Oake $\mathrm{N}$ et al. The effect of hospitalization on oral anticoagulation control: a population-based study. Thromb Res 2007;119:705-I4

67. Chamberlain MA, Sageser NA, Ruiz D, et al. Comparison of anticoagulation clinic patient outcomes with outcomes from traditional care in a family medicine clinic. J Am Board Fam Pract 2001;14:16-2I.

68. Sawicki PT. A structured teaching and self-management program for patients receiving oral anticoagulation: a randomized controlled trial. JAMA I999;28I:I45-50.

69. Hasenkam JM, Kimose HH, Knudsen L, et al. Self management of oral anticoagulant therapy after heart valve replacement. Eur J Cardiothorac Surg I997;II:935-42.

Correspondence to: Natalie Oake, Clinical Epidemiology Program, Ottawa Health Research Institute, Room C4I4, Ottawa Hospital, Civic Campus, 1053 Carling Avenue, Ottawa ON $\mathrm{KIY}_{4}$ E9; fax6I3 76r-5492; noake@ohri.ca
Appendix 1: MEDLINE and EMBASE search* strategy for study

\begin{tabular}{|c|c|}
\hline Step & Instruction \\
\hline 1 & exp ANTICOAGULANTS/ (131802) \\
\hline 2 & Anticoagula\$.mp. (55468) \\
\hline 3 & exp ADMINISTRATION,ORAL/ (88682) \\
\hline 4 & oral.mp. (334698) \\
\hline 5 & acenocoumarol.mp. (896) \\
\hline 6 & dicumarol.mp. (1381) \\
\hline 7 & ethyl biscoumacetate.mp. (169) \\
\hline 8 & phenprocoumon.mp. (762) \\
\hline 9 & warfarin.mp. (12504) \\
\hline 10 & OR/1-9 (476521) \\
\hline 11 & INTERNATIONAL NORMALIZED RATIO/ (1533) \\
\hline 12 & inr.mp. (2486) \\
\hline 13 & international normalized ratio.mp. (2589) \\
\hline 14 & OR/11-13 (3762) \\
\hline 15 & exp HEMORRHAGE/ (168493) \\
\hline 16 & exp CEREBROVASCULAR ACCIDENT/ (39071) \\
\hline 17 & exp EMBOLISM/ (62296) \\
\hline 18 & exp THROMBOSIS/ (101547) \\
\hline 19 & exp VENOUS THROMBOSIS/ (31893) \\
\hline 20 & exp ISCHEMIA/ (374821) \\
\hline 21 & exp BRAIN ISCHEMIA/ (39646) \\
\hline 22 & exp CEREBROVASCULAR TRAUMA/ (3189) \\
\hline 23 & hemorrhage.mp. (144980) \\
\hline 24 & bleed\$.mp. (84122) \\
\hline 25 & stroke.mp. (90045) \\
\hline 26 & thromboembol\$.mp. (29818) \\
\hline 27 & OR/15-26 (753203) \\
\hline 28 & 10 AND 14 AND 27 (1960) \\
\hline
\end{tabular}

*Last searched 2006 Oct 27 